\title{
Bangladeshi, Indian, and Pakistani Parents' Perceptions of Their Children's Academic Achievement in Southwest Florida
}

\author{
Shahid Rasool ${ }^{1}$ and Jingshun Zhang \\ Florida Gulf Coast University, USA
}

\begin{abstract}
Bangladeshis, Indians, and Pakistanis (BIPs) are among the highest educational and financial achievers in the United States with unique cultural and behavioral patterns. Despite the significant signs of economic and educational achievement, BIP individuals have remained an understudied population. The purpose of this qualitative study was to understand the experiences and perceptions of BIP parents via semi-structured interviews to explore key factors related to parental involvement behaviors in children's academic achievement. The data collection process included semi-structured interviews, observations, and field notes, in order to compose a rich narrative description from the findings and the researchers' interpretations of the phenomenon. The data were incorporated into thick, rich descriptions of the perceptions and experiences of the participants. After coding and using thematic analysis, three themes emerged: parents' behavioral trends, parents' roles and families' cultural values. The implications will help stakeholders and policy makers to select or develop family-school programs that further encourage this group to be involved in their children's education.
\end{abstract}

KEYWORDS: Parental Involvement, BIP Immigrants, Children's Academic Achievement, Hoover-Dempsey and Sandler's Model, Semi-Structured Interview.

The degree to which children's potential can be realized, depends a great deal on the environments within which they develop and learn as well as the interconnectedness between these environments (Patrikakou et al., 2005). A child's social, emotional, and cognitive development is greatly influenced by the family and by the relationships formed among family members. The influence of parental engagement in student success was first studied in the early 1980s and became a critical component in educational research studies pertaining to parental involvement and children's academic achievement (Henderson \& Berla, 1994; Hoover-Dempsey \& Sandler, 1997, 2005; Levin \& Aram, 2012; Yuen, 2011). Despite consistent encouragement by federal and local education agencies and policies, however school officials are still facing challenges in defining and measuring parental involvement in ways that would assist in the development of parental involvement policies and programs (Lau, 2013). Part of the difficulty is the different and varying means by which parents contribute to their children's lives at home and at school (Jeynes, 2012). However, the quality of parenting and the home learning environment are the most influential factors in children's development in the early years (Hartas, 2015).

${ }^{1}$ Corresponding Author E-mail: srasool1201@eagle.fgcu.edu 
The study of parents' attitudes is relevant in this domain because a person's attitude is associated with choosing a certain behavior (Ajzen, 2002, 2015; Ajzen \& Fishbein, 1972). This means parents' attitude guide their behaviors to be engaged in their children's educational activities. Parental attitude is associated with parents' engagement in children's education at home and in school-based activities, and this relationship has been extensively studied (Ali, 2011; Hill \& Tyson, 2009; Hoover-Dempsey et al., 2005; Patel \& Stevens, 2010; Uddin, 2011). Therefore, an exploration of parental attitude toward child's educational activities at home and at school can improve student academic achievement. The current study focused on investigating the experiences and perceptions of parents regarding their children's academic achievement in families belonging to the three largest South Asian countries Bangladesh, India, and Pakistan (BIP). The researchers sought to accomplish the purpose of this study by exploring the research question that undergirded it:

- What are the experiences and perceptions of Bangladeshi, Indian, and Pakistani parents that contribute to their children's educational achievement?

\section{Background Information}

Very diverse student populations populate public schools in the United States. As such, school leaders benefit from knowing what family factors from their diverse communities contribute to student success. Parents can contribute to their children's academic achievement by providing a safe and friendly home environment, communicating high expectations, and becoming engaged in children's educational activities (Henderson \& Berla, 1994). Parents' expectations and children's academic outcomes are dependent on family characteristics, beliefs and parental support behaviors (Epstein, 2001). Likewise, Ogbu (1992) conducted a study and found that out-of-school activities and parental attitudes influenced children's educational outcomes and priorities.

The South Asian population can trace its roots to diverse Indian subcontinental regions, each possessing and exhibiting unique characteristics, languages, religious beliefs, and cultural backgrounds. Asian Americans (as a major group) and South Asian Americans (as a sub-group) have been identified as the fastest growing racial groups in the United States, surpassing the number of Hispanic immigrants, and growing 46\% from 2000 to 2010 (Pew Research Center, 2017; U.S. Census, 2010). In the same context, Asian Americans have the highest median annual household income among all U.S. households while South Asians are among the highest earning subgroup within Asian Americans. Furthermore, while only 30\% of all Americans 25 years of age and older possessed a bachelor's degree or higher in 2015, South Asian Americans had the highest level of educational attainment when compared with White, African Americans, and Hispanics, as shown by the percentage who hold a bachelor's degree or higher. Analysis of census data revealed that over $72 \%$ of Asian Indians, 55\% of Pakistanis and over $51 \%$ of Bangladeshis had completed college degrees (Pew Research Center, 2017). Structural and cultural factors such as beliefs, values and behavioral patterns have a significant impact on the economic and academic success of various ethnic groups (Paik et al., 2017).

Before the partition of the Indian sub-continent in 1947, Bangladesh, India, and Pakistan (BIP) were one country. Therefore, they exhibit similarities in language, culture and religious beliefs. However, the literature lacks regional studies based on the behavioral characteristics, socioeconomic status and cultural differences of parents from South Asian countries, including BIP. The population of Bangladeshis, Indians, and Pakistanis will continue to grow more rapidly than other Asian populations in the United States (Pew Research Center, 2017). Therefore, this 
current study was conducted in order to investigate Bangladeshi, Indian, and Pakistani parents' experiences and perceptions of behaviors that contribute to their children's academic achievement.

\section{Literature Review}

Behavior patterns are developed and sustained when behaviors are consistently associated with positive outcomes (Skinner, 1989). For example, parents' assistance with homework is reinforced when it enhances their child's academic outcomes, which turn allows the child to achieve their educational goals and careers. Parents assist their children to enhance student learning through the sharing of information and home-based activities that complete school related tasks in home settings. In addition, parental involvement behaviors help children at home tend to influence student outcomes in a positive manner (Hoover-Dempsey \& Sandler, 2005). Moreover, parental assistance at home may include completing learning tasks, providing support and resources, refining learning strategies or assisting students with homework (Hill \& Chao, 2009). These interactions can help develop problem-solving skills and student's academic self-efficacy (Gonida \& Cortina, 2014; Walker et al., 2010). Parents' participation in home-based learning activities such as assistance in homework, problem solving, explaining information, and answering questions can help parents to understand their children's learning processes (Ginsburg et al., 2008; Henderson \& Mapp, 2002; Hoover-Dempsey \& Sandler, 2005). Parental engagement in children's education is vital and has been termed "participation in school activities" by some researchers (Coleman \& McNeese, 2009); while some have viewed it as "parental aspirations and expectations for their children" (Hill \& Tyson, 2009), and others as "assistance in homework" (Hoover-Dempsey \& Sandler, 2005). Some parents may not be able to assist in homework for various reasons such as their own educational limitations, other family obligations, and limited time, and resources (McGregor \& Knoll, 2015).

Researchers have found that parents can contribute to their children's academic achievement by providing a safe and friendly home environment, communicating high expectations, and becoming engaged in their children's educational activities (Henderson \& Berla, 1994). Parents need to invest and be involved not only in academic achievement but also in the development of their children's personalities. The two key factors that play significant role in parental involvement and children's academic achievement are: (a) family environment and (b) family background (Roy \& Giraldo-Garcia, 2018). The idea of producing self-confident and hardworking successful children through intensive parenting has been gaining popularity across several industrialized countries (Doepke \& Zilibotti, 2019). However, with the increased division of labor and rapid technological changes, many parents have willingly granted children more freedom of choice to develop human capital through formal education (Doepke \& Zilibotti, 2017). In the same context, children perform better academically when parents can keep a balance between coercive and permissive behaviors and provide a compatible home environment (Baumrind, 1966). The relationship between family structure and a child's academic development can be best understood when other siblings are considered alongside parent-child relationships (Mostafa et al., 2018). In a qualitative study in which a large number of single parents and/or primary caregivers of the children were interviewed, Lechuga-Pena and Brisson (2018) found that single parents could not provide needed attention and love to each of their children due to a lack of time and energy. In contrast, parents' perception of deficits in their children's experiences at school tends to increase their involvement to enhance their children's educational outcomes (Park \& Holloway, 2018). Furthermore, a parent's educational level is considered a determinant of their involvement in their children's education along with other family demographic characteristics (Wang et al., 2016). 
Thus, parents' educational levels can have an effect on the academic development of their children if parents show aspirations and motivation in their children's education (Yildirim, 2019).

For the last 50 years, parental involvement has been a critical element in educational outcomes and in children's well-being at all different levels (Arias \& Morillo-Campbell, 2008; Beauregard et al., 2014; Epstein 2001; Hill \& Tyson 2009; Hornby \& Lafaele, 2011; Jeynes, 2011; Vera et al., 2012; Wilder 2014). Various types of parental involvement include home-based parental involvement in the form of assisting children with homework and providing resource support. School-based parental involvement includes participating in different academic activities at school and attending parent-teacher meetings (Harris \& Goodall, 2008). Over several years, researchers have recognized the value of family-school partnerships and have investigated various aspects of parental involvement in their children's academic achievement (Dearing et al., 2006; Epstein, 2001; Jeynes, 2012). In addition, some studies have found that socioeconomic status and parents' educational levels affect the degree of parental involvement behaviors, student enrolment, and children's academic achievement (Coleman et al., 1966; Jeynes, 2015; Lee \& Bowen, 2006; Lindberg \& Demircan, 2013). However, an in-depth understanding of various levels of parent involvement and the different factors influencing parental involvement behaviors among BIP families is needed. What is evident from the literature is that family is the most important informal structure that may affect a child's academic outcomes and social development (Baker \& RimmKaufman, 2014; Blair, 2014; Kuru \& Taskin, 2016).

The U.S. population has shifted dramatically in the last 50 years, which is reflected in the changing face of American schools (Benner \& Yan, 2015). Data has indicated that approximately $70 \%$ to $90 \%$ of the student population of major cities such as Los Angeles, San Francisco, Chicago, New York, and Miami, is comprised of bicultural students (Darder, 2016). In the same context, in 2017, a total of $50 \%$ of all public-school students were students of color (Friend, 2018) and the proportion of White students is projected to continue decreasing from $48 \%$ to $44 \%$ (National Center for Education Statistics, 2020). However, there is limited research on parents from diverse cultural backgrounds pertaining to parental involvement behaviors and engagement in their children's educational activities (Pinder, 2012). A record 20 million people of Asian origin live in the United States, trace their roots to 20 different countries in East, Southeast, and South Asian regions. South Asian people come from India, Pakistan, Bangladesh, Sri Lanka, Nepal, Bhutan and the Maldives. The current population of South Asian region is over 1.9 billion, while the majority 1.766 billion live in BIP, based on the latest United Nations estimates (World O meters, 2020).

South Asian immigration to the United States took place in three major waves, that started in the early 1900s. In the first wave, the number of South Asian immigrants were estimated in the few thousands. They came between 1897 and 1924 from the Punjab province in India (Bhattacharya \& Schoppelrey, 2004; Leonard, 1997). With the passage of the Immigration and Nationality Act of 1965 to meet the needs of the labor market, the second wave of South Asians and their families immigrated to the United States pursuing education, work, business, and a better quality of life (Patel \& Stevens, 2010). The new immigration laws prioritized highly skilled and wealthy professionals, such as scientists, doctors and engineers and their families (Bhattacharya \& Schoppelrey, 2004; Purkayastha, 2005; Saran, 2007). Consequently, a majority of these South Asian immigrants had college degrees and were urban middle-class professionals or students seeking higher education. As a result of the Immigration Reform and Control Act (1986) and the Immigration Act of 1990, the third wave of immigrants brought a significant demographic shift (Pew Research Center, 2015). Although, skilled workers, professionals and students continued to arrive, the vast majority of this wave of South Asian immigrants were less educated, and less fluent in English in comparison with their predecessors (Sandhu \& Madathil, 2008). Due to equivalency 
and recertification issues, many immigrants with foreign post-secondary credentials were unqualified or underqualified for better jobs in the United States. These individuals found blue collar jobs and started working as taxi drivers, grocery store clerks, motel operators or small store owners (Bhattacharya \& Schoppelrey, 2004; Verma, 2008).

Parents behaviors aimed at engaging in their children's education depend on the expectation parents have of their children (Eng et al., 2014). Cultural differences, parents' expectations for their children's success, behaviors among the parents' peers and the child's academic achievement may influence parental involvement behaviors (Raty \& Kasanen, 2010). The cultural differences regarding collectivism and individualism between South Asian Americans and European Americans may be hard to understand for adolescent children when it comes to making important life decisions (Berrington, 2018; Iqbal \& Golombok, 2018; Lalonde et al., 2004; Rahman \& Witenstein, 2014). Children tend to behave in accordance with their parents' beliefs about educational competence. Parents expectations and attitudes toward education play a critical role in their children's academic performance (Enlund et al., 2015). In the early stages of a child's schooling, parental expectations are dependent on personal factors but as the child grows and move in higher grades, their expectations depend on their child's academic performance (Yamamoto \& Holloway, 2010). Martinez (2010) was convinced that parents can contribute to their children's educational outcomes by passing along certain values and behaviors. Parents who expect their children to perform better at school and parents with stronger beliefs in and higher expectations for their children are highly likely to provide resources and support at home for their children (Sy \& Schulenberg, 2005). Data has reflected that South Asians expect their children to perform better and achieve higher education compared with European Americans. It is estimated that parents' expectations for their children to earn a bachelor's degree increased from $61 \%$ to $89 \%$ between 1984 and 2007 for South Asian Americans while it rose from 38\% to 72\% for European Americans over the same period (Child Trends, 2015).

Despite differences in religion, language, and geographic origins, BIP people shared common traditions, cultural values and family beliefs (Shariff, 2009). The common cultural values among BIP people have existed since 7000 B.C., long before the current geographical borders of these countries (Ibrahim et al., 1997). Living a common way of life for centuries explains why a shared culture has continued to exist among the people of BIP across nationalities, religions, and geographical borders (Shariff, 2009). In order to fully comprehend parental involvement behaviors among Asian families (various subgroups), it is imperative for educators and teachers to understand the role that culture plays within Asian families in their children's educational achievement (Otto, 2016). The cultural values of an ethnic group influence parental involvement behaviors and their role in children's education (Chao, 2000). Family closeness and cohesion is associated with children's academic achievement (Chao, 2000, 2002). Cultural differences in parenting style, decision-making, and control over children, and their influence on children's education has been controversial (Kwon et al., 2017). A strict parenting style has been found to play a negative role (Bradley-Geist \& Olsen-Buchanan, 2014; LeMoyne \& Buchanan, 2011; Schiffrin et al., 2014; Segrin et al., 2012; Wang et al., 2007) while parental behavioral control with autonomy support has a positive influence on children's academic achievement and emotional development (PadillaWalker \& Nelson, 2012; Wang et al., 2016).

In summary, the previous literature has shown that parents' decision to be engaged in their children's learning is a multifaceted phenomenon since parents become involved in their children's educational achievement in a variety of ways and in various locations. Parents support their children by providing a safe home environment, assisting students with their homework, helping children in making decisions at school, and helping them to avail themselves of community 
opportunities. Parental engagement in their children's education depends on the expectations parents have of their children. The breakdown of the family unit can have a significant impact on children's lives in many ways. Thus, school leaders would benefit from being informed about family factors in diverse communities that contribute to student academic success.

\section{Theoretical Framework}

The theoretical framework of this study is grounded in Hoover-Dempsey and Sandler's model of parental engagement behaviors (1997). By adopting the Hoover-Dempsey and Sandler's model (1997), researchers can examine the level of parental involvement behaviors that involve parents in their children's academic activities at home and school. Hoover-Dempsey and Sandler's (1997) model proposes three motivational sources that influence parental involvement behaviors in their children's educational activities. (a) Parents' motivational beliefs that inspire them to play a constructive role in promoting their child's learning in school, (b) a perception of school climate that motivates parents to establish a productive reciprocating relationship with teachers, and (c) personal life context factors that influence the ability of parents to be engaged in their children's academic activities. The third source is based on the self-efficacy, time, and energy of parents that is required for participation in their children's educational activities. Additionally, family culture factors into parental involvement behaviors and school leaders should respect family culture and home environment in order to fully empower parents in the student learning process (HooverDempsey \& Sandler, 2005).

Parental involvement behaviors enhance student academic achievement by contributing to the development of academic skills such as planning, monitoring, and regulating the learning process (Pomerantz et al., 2007). Parents' motivational beliefs include beliefs about school and beliefs about their personal ability to be effective at home in their child's education (HooverDempsey \& Sandler, 2005). Hoover-Dempsey and Sandler's model (1995) does not simply provide a model for parental engagement rather, it attempts to explain fundamental reasons behind parental engagement behaviors and the processes through which parental engagement influences students' educational outcomes in a positive way (Fan \& Chen, 2001).

\section{Research Method}

Qualitative studies deal primarily with words and are used when researchers are seeking to further explore situations and events from the viewpoints of the participants (Fraenkel et al., 2015). The researchers employed a qualitative research method to gain deeper insights and to investigate BIP parents' experiences and perceptions of their children's academic achievement. A phenomenological approach allowed researchers to suspend their own attitudes and value judgements while attempting to represent the experiences and perceptions of participants (Creswell, 2014; Denzin \& Lincoln, 2011; Husserl, 2012; Moustakas, 1994; Padilla-Diaz, 2015; Patton, 2002; Yin, 2016). Semi-structured face-to-face interviews allowed for an understanding of the subjective experiences and perceptions of individuals in order to develop a composite description of what and how they experienced the phenomenon (Butler, 2016; Creswell, 2007; Husserl, 1970; Moustakas, 1994).

In order to test the interview protocol, a pilot study was conducted in March 2020. As a result of the pilot study, few questions were re-ordered, reworded to eliminate biases, and amended for clarity (Rasool et al., 2020). In semi-structured face-to-face interviews, the participants were asked about their parental involvement experiences and their perceptions of the impact of their 
involvement in their children's academic achievement. Some example questions included, what are the specific trends of parental involvement behaviors and cultural values that contribute to your child's academic achievement? What are some of your behaviors that you think encourage your child in academics achievement? What are your academic expectations and how do you communicate your expectations to your child? Do you set rules pertaining to socializing with friends, screen time/social media or TV? Do you know your child's friends and their families? Participants were also asked to share other thoughts, experiences and perceptions in relation to their involvement in their child's academic achievement. Member checking was done when the researchers asked the participants to review their data, findings, and interpretation to verify the accuracy of the content. This helped to establish the credibility, reliability, and confirmability of the product (Creswell, 2013; Lincoln \& Guba, 1985). In the same context, member checking was performed after identifying the emerging themes across the qualitative data, field notes, and evaluations by the researchers sharing the interpretations, emerging themes, and findings with the researchers (Creswell, 2014). In order to support the validity of this qualitative research, a peer review method was also followed (Creswell, 2015). In the peer review process, external auditors reviewed the research process, data collection, and data analysis (Creswell, 2013; Lincoln \& Guba, 1985; Patton, 2002). For the pilot study and the main research project, a faculty member who was an expert in qualitative research and two fellow doctoral candidates served as a peer review team and assisted us throughout the research processes.

\section{Research Design}

BIP parents/guardians belonging to various socioeconomic and educational groups were invited to participate in face-to-face interviews to share their experiences and perceptions pertaining to their parental involvement behaviors in their children's educational achievement (Creswell, 2012; Merriam, 2009). The open ended, face-to-face interview is a method of extracting information that best represents participants' experiences and perceptions of the phenomenon (Clandinin \& Connelly, 2000). In addition, field notes were compiled between questions during the interviews (Creswell \& Poth, 2018). The data were transcribed, coded and developed into themes to further reinforce validity and reliability of the findings of triangulation. These provided a basis for triangulation in order to ensure the confirmability of the findings. Finally, the researchers employed peer review technique and used external panel of experts who understood the nature of this study and had prior knowledge of the phenomenon (Creswell \& Miller, 2000).

\section{Participant's Background}

A purposive sample of 10 parents (six male and four female) from BIP origin was recruited to participate in face-to-face interviews. These participants were living in Southwest Florida, with children currently studying in K-12 public schools. The southwest Florida region includes Lee County and parts of Manatee, Collier, Sarasota, and Charlotte Counties. In this study, there were three parents with a Bangladeshi ethnic background, three with an Indian background, and four with a Pakistani ethnic background. Historically, BIP immigrants have been considered appropriate for a regional study because these individuals tend to maintain their cultural values at home and focus on academic excellence and economic stability (Ahmed, 2005; Giguere et al., 2010). In addition, participants also reported their age which ranged from 33 to 53. Participants' demographic information is given in Table 1. For the purpose of confidentiality, each parent was numbered one through ten and called parent 1, parent 2, parent 3 and so on. These pseudonyms 
were assigned to replace the parents' names. What follows is a structural description based on the analysis of each participant's interview content that was used to develop various themes. For instance, the majority of the parents reported that they sacrificed to provide a better life for their children. This sacrifice could be in terms of time, money, sleep, or the career choices parents made to become involved in their children's educational activities.

Table 1

Basic Demographic Information of BIP Participants

\begin{tabular}{lcccc}
\hline Participant & Age & Gender & Country of Origin & Location (County) \\
\hline Parent 1 & 53 years & Male & India & Charlotte \\
Parent 2 & 39 years & Female & Pakistan & Lee \\
Parent 3 & 45 years & Female & Pakistan & Lee \\
Parent 4 & 46 years & Male & Pakistan & Collier \\
Parent 5 & 38 years & Male & Bangladesh & Sarasota \\
Parent 6 & 52 years & Male & Bangladesh & Lee \\
Parent 7 & 33 years & Female & India & Charlotte \\
Parent 8 & 36 years & Male & India & Manatee \\
Parent 9 & 41 years & Male & Pakistan & Collier \\
Parent 10 & 44 years & Female & Bangladesh & Lee \\
\hline
\end{tabular}

\section{Data Collection Process}

The data collection process included in-depth, semi-structured interviews, observations, and field notes taken during the interviews (Yin, 2005). These data sources allowed the researchers to compose a rich narrative description based on the findings and allowed them to interpret the phenomenon to answer the research question. These willing parents/guardians participated in a face-to-face interview at a place and time of their choosing which lasted approximately 35 minutes. The interviewees shared their feelings, opinions, and attitudes towards their experiences and perceptions of involvement in their children's academic achievement (Creswell, 2014). The field notes were taken to register the behaviors, reactions, and facial expressions of the participants during the investigation of a particular theme. The combination of interview content and fieldnote data ensured deeper insights into the participants' perceptions (Yin, 2005) and increased the trustworthiness and credibility of the findings (Creswell \& Poth, 2018).

\section{Ethical Considerations}

Ethical isues considered as a priority during the design and implementation of all the processes in this research study (Creswell, 2015; Fleming \& Zegwaard, 2018). To ensure the ethical treatment of participants, secure data collection and storage, and reflexive research (Cain et al., 2019), an IRB approval (\#S2020-16) was obtained. All participants signed a consent letter indicating their willingness to participate and researchers used pseudonyms to ensure confidentiality (Creswell, 2014). Internal validity was established through triangulation involving multiple methods, multiple sources, and member checking (Lincoln \& Guba, 1985), as well as through bracketing researcher bias, and reflexivity. In addition, peer reviews were utilized. 


\section{Data Analysis}

Through the open-ended, semi-structured interviews, the researchers sought to gain more in-depth insights into parents' experiences and perceptions of their behaviors related to their children's academic achievement (Creswell, 2013; Johnson \& Christensen, 2020). The semistructured interviews were recorded, transcribed verbatim, and then distributed for member checking and confirmation. To initiate the coding process, the researchers thoroughly examined the participants' interview question responses. After a comprehensive investigation, portions of the data set were selected that were strongly associated with the personal experiences of the participants, and the essence of the phenomenon (Creswell, 2013). Significant statements such as individual experiences of parental involvement behaviors and the context of those experiences were highlighted to create code names, including information researchers expected to find, information that was surprising, and information considered noteworthy (Creswell, 2014). The researchers analyzed the data sources for these codes, discussed the common ideas (Creswell, 2013) and grouped them into three themes (Creswell \& Plano Clark, 2018; Miles \& Huberman, 1994). Finally, direct quotations from the data were incorporated into the thick, rich descriptions of the perceptions and experiences of the participants (Creswell \& Poth, 2018; Johnson \& Christensen, 2004). Thick rich description enhanced the reliability and transferability of the research as it provided a deeper insight into the phenomenon, setting, and other processes of this study. The readers might not glean such detailed information if limited reporting was permitted. The whole process allowed the researchers to write a narrative to explain "what happened" and "how" the phenomenon was experienced (Creswell, 2013).

Furthermore, the researchers continued to analyze the data extensively from the time they were transcribed until major themes had emerged repeatedly. The researchers maintained the accuracy and integrity of the process because the information was not drawn from a single source or individual (Creswell, 2007). The data analysis process focused on the content of each interview and a comprehensive analysis of all data was ensured (Bogdan \& Biklen, 2003).

Figure 1

An Overview of Various Levels of the Coding Process

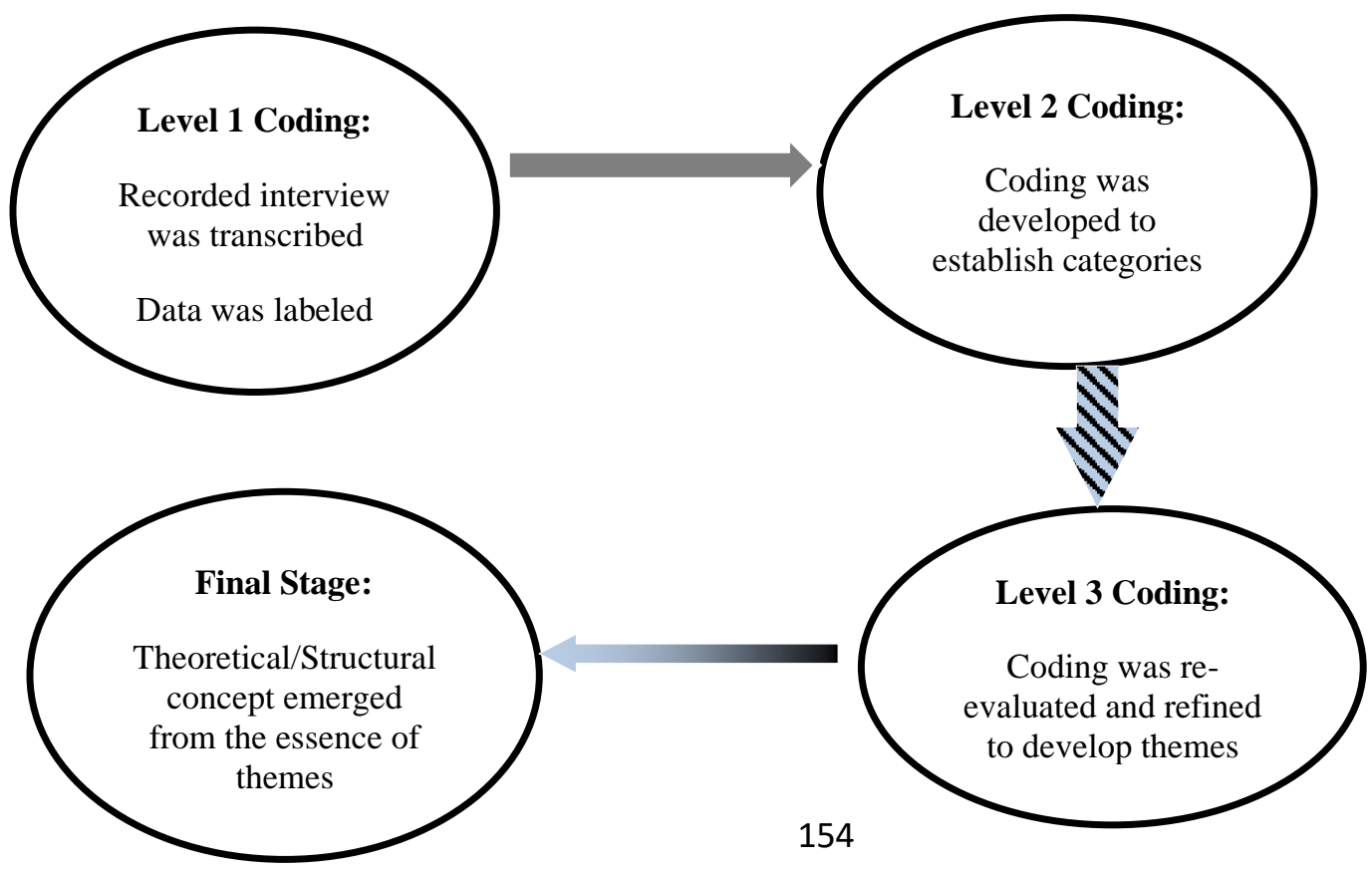




\section{Structural Description}

The parents' experiences and perceptions of their behaviors pertaining to their children's educational achievement, originated from: (a) beliefs about self-discipline, (b) beliefs about the value of education, (c) parents' significant sacrifices, (d) parents' hard work, (e) the influence of other family members, and (f) comparison with other children in the community. In short, the compiled common meanings or themes developed by the researchers from the analysis and coding of all the responses comprised various behaviors and beliefs the parents possessed in relation to the educational activities of their children. The majority of the parents expressed that they believed their role was an important factor in their children's educational achievement. Parents described their role in various terms, such as: (a) providing guidance to their children in selecting a career path, (b) assisting their children with homework, (c) providing their children with all the necessary resources such as books, and computers, and (d) enforcing rules to ensure their children stayed focused on their studies. Parents also voiced their role in setting academic expectations for their children and making sure to communicate these expectations effectively.

The common findings derived from the participants' responses and expressions pertaining to their children's educational achievement, were united by the theme of family and cultural values. Parents showed significant concern for and monitored their children's activities on social media, their social activities with other children, their choice of friends, the family values of their children's friends, and their children's maintenance of a close connection with their native language and traditions. See Table 2 for a brief summary of various structural descriptions and themes. 


\section{Table 2}

Description of the Experiences and Perceptions of BIP Participants $(N=10)$

Interview Questions Themes

What are your family's
special behavioral trend
and cultural
characteristics?
trends that encourage your child in education?

, Behavioral trends (self-discipline)
- Cultural characteristics (family
influence)
Cultural characteristics
Participants duplicated several behaviors displayed by their
parents

Statements

Number of Parents for

each Theme

- (parent's sacrifices)

, Consistent hard work will help to achieve academic

excellence

- Cultural \& behavioral trends in

communication about expectations , I will retire in as soon as my son graduates from medical school

Call me selfish, but I want my daughter to study what I will plan for her

- I want my child to value everything they have such as clothing, food, safe home environment, comfortable life. 'We did not have much when we were kids

, We consistently tell our kids what we expect

In what manner is your behavioral involvement

- Parents role in choosing career path (family influence)

- I want my daughter to fulfill my late husband's dreams and become a doctor

important in your child's academic achievement?

What factors hinder or

contribute to your

parental behaviors in

children's educational

activities at home and at

school?

- Parents role in education (hard work)

- Parents role in son's education over daughter

- Role model (value of education)

, I have been telling my children what kind of career line they should adopt since they were little

- I consistently asked them to get good grades and nothing less than ' $\mathrm{B}$ '

- I expect my son to do better than my daughter, so I tell him to work harder than his sister

, I want to be a role model for my children. I want them to work hard in their education

- Being a single household provider, I must work long hours to

- Parents role in providing help with math provide for my family and do not find time to help my kids

, My kid needed help with math and school has helped my son.

, I hired a private tutor
All parents unanimously
agreed

Parents $1,3,5,6,9$

Parents 2,4,5,6,10

Parents $1,2,5,7,8$

Almost all participants

Parents 2,3,5,7,9

Almost all the participants

Parents 2, 6

Almost all participants

Almost all participants

Parents 2,4,5,6,8

Parents 3,7,10 
Do you set rules pertaining to socializing

with friends, screen

time/social media or TV

Do you know your

child's friends and their families?
Cultural characteristics in imposing restrictions (selfdiscipline)

- Cultural characteristics in socialization with friends

- Cultural values- Approve/ disapprove of child's friends' family
Yes, enforced screen time

- Enforced social time

- We restricted sleep overs outside our own house

- Yes, we do "screen" friends and make sure they have same values as we do

' We do enforce rules about not having sleep overs at friends' houses

- Friends from other ethnic backgrounds are not at the child's birthday party

- We ask our child not to spend time with some friends because of different family values

- Our kids should take care of us in our old age (one reason for them to get education)

Any other thoughts or

experiences related to
children's performance?

- Parents behavioral trends, parents' role and cultural values in making

choices for children
Children do not know much; parents should decide their career path
Almost all participants

Almost all participants

All participants

All participants

Parents 2,3,5,7 


\section{Findings}

The purpose of this study was to answer the research question which focused on the experiences and perceptions of Bangladeshi, Indian, and Pakistani parents of their behaviors that contributed to their children's educational achievement. The findings of the thematic analysis of the qualitative data collected via face-to-face interviews showed that parents perceived a connection between providing good education and their children's future success. The results were reached based on information drawn from various sources (Creswell, 2007), and the researchers substantiated and confirmed all the evidence to support emerging themes. Consequently, three thematic categories from the face-to-face interviews, observations, and field notes emerged, including (a) parents' behavioral trends, (b) parent's role, and (c) parents' cultural values.

\section{Theme One: Parents' Behavioral Trends}

The parents in this steady provided key information and useful data concerning their beliefs and family values pertaining to their children's academic achievement. Behavioral trends are prevalent in South Asian immigrants and are visible in their lifestyles (Bhattacharya \& Schoppelrey, 2004; Tran et al., 2005). In addition, parents from Bangladesh, India, and Pakistan tend to be engaged in their children's daily after school activities. Parents, in aspiring to motivate their children to achieve higher grades, constantly compared their children with their siblings, other family members, and other children in the community. One parent expressed:

My cousin's three of five children are in med school. I want to make sure my children get good grades and work hard to compete with them and follow their footsteps to become doctors. Although, I want my kids to get 'A' grades and ' $B$ ' is also okay, however, 'C' grade is totally unacceptable.

Generally, BIP parents placed a high value on education as evidenced by their involvement behaviors. Most participants agreed that earning higher degrees could lead to a successful career and more comfortable lifestyle. Therefore, many parents were convinced that children need to focus on their educational goals and spend less time on social media, watching TV, or socializing with friends. Parents also wanted to know the families of their children's friends in order to make sure the family values and behavioral characteristics were compatible between them. One parent voiced:

I am always concerned about my children's friends and families. I make sure I know their educational priorities and family values. In the past, I have stopped my children from making friends based on families' educational priorities and values.

Additionally, some parents reported that they valued hard work and self-discipline. The parents further added that they wanted to have a similar family environment to the one they were given as a child by their parents. One parent stated that:

My parents made sure that I did all my homework and chores around the house. Now, as a parent I am trying to enforce the same values and discipline with my children. As it has worked for me, I believe it should 
work for my children as well. I think it is like an example of a wheel turning; once a wheel starts turning and you make sure it is in motion then it will never stop. So, the next generations need to keep the same momentum and trend to progress in life.

Aside from the aforementioned behaviors, seven out of the 10 parents said that hard work was a part of their family environment or a key personal behavior. The majority of these parents expressed that children need to work hard to achieve their educational goals particularly high grades. One parent believed that

Hard work is important and has always been my virtue since I arrived in this country. I have worked long hours every day to provide for my family. I believe my children should notice how much do I do for them and they should bring these values to achieve better grades so they can be successful in life.

Another parent mentioned that adaptability and hard work are two interconnected factors and key characteristics of his family. He further stated that:

My parents migrated during partition of India from a major city which is now in Pakistan, to a province which is now a part of India. They started their life from nothing. The major factors behind their existence were hard work and adaptability to new culture and environment. This is very true for me and my family as well after moving from India to the U.S. I am making sure that my children develop same values of adaptability and hard work in this country to lead a successful life. I fully understand that there are huge differences between the two countries (India and the U.S.) but with hard work, adaptability, and perseverance my children should be able to achieve their educational goals in order to be successful in life.

Some other parents shared similar behavioral trends in relation to their children's academic achievement and career goals.

\section{Theme Two: Parents' Role}

Concerning this theme, the participants discussed the parental role as a key to the success of their children. Due to the strong interdependency and hierarchical characteristics of Asian family structures, South Asian Americans practice parental authority and family honor. Therefore, parents play a significant role in everyday life, in educational decision making and in selecting career goals for their children (Dutt, 2009; Ngo, 2006; Pew Research Center, 2012). A father explained:

I would like to manage my kids' lives until the end. I will make sure they choose an educational career that enables them to find jobs locally and could possibly stay in the same neighborhood. So, I can help them with their needs even after they are married and have their own families. 
Another parent expressed similar reasons to be involved in his children's academic activities. He explained how his presence in his child's life was important in her educational achievement. He voiced:

I often discuss college plans for my seventh grader. She does not want to attend college in Florida. She always wants to go to North to attend Harvard University, Boston College, or other big school in North. Therefore, we are planning to move out of Florida so we can stay closer to our daughter and provide her housing while she goes to school. I do not want her to live alone and I want to be there to protect her. I believe this is what parents' role should be in their children's lives. I also explained her that in order to get into a good school in North, she must work hard and must get good grades starting from middle school. In addition, I am not very rich to pay for these expensive schools. Therefore, she needs to have good grades to earn full scholarship to get in Harvard University or any other big college in North.

Parents often reported feelings and concerns about their children spending time on social media, screen time, and online gaming and activities. Five out of the 10 parents mentioned something similar to this parent:

We control media time/screen time and online gaming time by shutting off Wi-Fi during the weekdays. The children can use digital devices strictly for homework and school assignments. Children must earn their time to use technology for recreation once they are done with their homework. If they do not follow the rules, we shut off Wi-Fi during their school days and turn it back on only on the weekends.

Another parent shared similar experiences when she talked about protecting her child from cyberbullying. She voiced:

I do not allow my daughter to attend home school during COVID-19 pandemic or to study with a closed door because I want to monitor her activities while she is attending online classes. I also check her iPad and iPhone when she is asleep to make sure she is not chatting with unknown people or she is not a victim of a cyber bullying from her peers.

The participants frequently highlighted the parents' role and how they offered their wisdom and guidance to their children to motivate them to attain good grades and achieve their educational goals. One parent explained:

I make sure that I communicate my expectations to my children on daily basis. Every time my child asks a question, I tried to turn it to highlight the value of education. When he asked me why I do not spend more time with him at home and outside to visit various places? I tell him that I must work long hours because I do not have a higher education to have a professional 
job. Therefore, he must have good grades and good education so that he can find a good paying job and not work hard, and long hours like me.

Similarly, another mother stated:

My late husband was a doctor and wanted to see my kids be a doctor.

Therefore, my daughter always wants to fulfill her father's dream.

A father made sure that he assisted his children with homework and other learning activities at home. However, some parents were unable to help their children due to a lack of self-efficacy while some complained about differences in the educational system. One parent explained:

In the early schooling years of my child, I was able to help him in mathematics and English. However, in the higher grades he was not able to assist with academic activities at home. I enrolled my child in an afterschool academy at $\$ 450$ a month per child. Sometimes it is a financial burden but as a parent I must play my role and continue to support my children to achieve better grades.

Many parents in this study thought that parents should be involved in every aspect of their children's lives due to their belief that their children's academic success and social status were reflections of successful parenting.

\section{Theme Three: Parents' Cultural Values}

An overwhelming majority of the participants shared how their cultural values were one of the main influences of parental involvement behaviors related to their children's academic achievement. South Asian parents and children have a reciprocal relationship of taking care of one another and the extended family (Chao \& Tseng, 2002). Parents maintain a strong work ethic in order to meet the needs of their children and, support them in achieving educational goals, finding a job or starting a family. In turn, children acknowledge an obligation towards their parents to take care of them in their later years. One parent said:

I will sell my retail business and retire in ten years once my son becomes a doctor and will take care of my financial needs.

Another parent shared a similar idea by emphasizing the sacrifices he made to meet the needs of his children and to provide for the family. He expressed:

I am working hard and long hours, so my children and family can have a comfortable life and be successful finding well-paying jobs. In turn, it is children's obligation to provide us (their parents) the same financial support when we grow old and unable to work.

The data indicated that participants believed that children should witness their everyday struggles and should study hard in order to attain a secure financial situation in the future. 
Furthermore, there was an emphasis on respecting elders in BIP families that influenced parental involvement behaviors related to their children's academic achievement. One parent explained:

I had serious issues with my child in selecting courses before preparing for college due to my older sibling's desire to study computer engineering. My son did not have any interest in pursuing a career as an engineer, but I could not disagree with my older brother. Now, my son is starting his business degree after convincing my brother, who showed great displeasure and disappointment.

Parents were also filled with fear when they thought of the negative impacts of the dominant culture on their children's lives. For example, their children would ask about participating in activities with their friends outside of school that might not be acceptable due to difference in cultures. One parent explained:

My daughter wanted to have a sleepover, but I always refused to let her spend a night over at a friends' house. I told her that in our culture girls are not supposed to stay out of the house for a night. Similarly, whenever she wanted to invite her friends in her birthday party, I am reluctant to do so because we have different family values and culture. It is sometime hard to explain why she is not allowed to do certain things her peers can do.

Many participants showed their agreement regarding collectivism and the importance of a joint family system that ensures strict discipline for academic success. Moreover, children's academic success and social and financial achievement are a source of pride and honor for the family.

\section{Discussion and Conclusion}

This study was an effort to investigate BIP parents' experiences and perceptions. It highlighted various factors influencing parental behaviors related to involvement in children's educational achievement for one of the highest achieving groups in the United States. The intent of recruiting BIP parents of K-12 students to participate in a face-to-face interview was to make sure the participants would be likely to have had several years of experience with involvement in their children's educational activities. Semi-structured face-to-face interviews of the participants provided deep insights into their experiences and perceptions of their involvement in their children's academic achievement. Therefore, one reason for this study was to broaden the knowledge base about South Asians' attitudes towards their children's education, as South Asians are a group that is excelling both professionally and academically in the United States. The findings of the current study were based on an analysis of qualitative data and reflect the process of immigrant success more comprehensively than the currently available literature.

The results of this study provided insight into the experiences and perceptions of BIP individuals about the academic achievement of their children. The study found that parents had high expectations for their children to achieve educational goals, and the findings reaffirmed that BIP parents place a high value on education, as evidenced by their behaviors (Bhattacharya \& Schoppelrey, 2004; Taylor \& Krahn, 2013). In particular, the lengthy interview data reflecting on parents' experiences and perceptions showed an apparent connection between parental behavioral 
trends and children's academic achievement. The findings of this study reaffirmed previous studies that consistently have identified a decline in many forms of parental involvement when children move into higher grades (Green et al., 2007; Hill et al., 2018; Seginer, 2006; Spera, 2005). However, parents get more involved in other activities such as choosing courses and career paths, planning learning strategies, and discussing plans for college (Chao et al., 2009, Hill \& Tyson, 2009). The findings showed that BIP parents also believed that education and a successful career would improve their children's standard of living and, ability to support their parents in old age, and provide a key source for the family's social mobility (Li et al., 2017).

The findings revealed that parents were closely involved with their children in home-based activities to improve their level of academic achievement. Such activities included the discussion of learning activities at school, assisting children with homework, time management issues outside of school, enforcing social media time, and TV screen time, and monitoring socializing with friends (Alghazo \& Alghazo, 2015; Henderson \& Mapp, 2002). The study highlighted that parents were highly involved in educational activities at home but were not very active in volunteering in classrooms, sports or other events at school (Yanghee et al., 2018). BIP individuals expressed a very close relationship with their cultural background, which was reflected in their behavioral trends such as socializing with families of a family with similar ethnicity, enforcing TV/screen time and setting minimum grade/GPA standards. The phenomenon of overparenting found in this study was in line with previous studies, regardless of parent demographics (Kwon et al., 2016; Segrin et al., 2015), that showed parents perceive this overprotection as contributing to the child's well-being (Kwon et al., 2017) and as a positive aspect of parenting (Padilla-Walker \& Nelson, 2012). Nevertheless, themes also emerged regarding cultural values, parents' roles, and parental behavioral trends pertaining to children's educational activities at home and at school.

\section{Implications}

It is possible for several implications about parental behaviors related to involvement in children's academic achievement can be derived from the findings of this research study. The findings of this study suggest a need for all stakeholders to have a clear understanding of parental beliefs and various factors that influence parental involvement in their children's academic achievement for one of the fastest growing ethnic groups. For instance, educators may not fully understand how cultural characteristics, family values, behavioral trends, and the parental role held by BIP parents play out concerning students' academic performance. The current study further points towards implications for practice and opportunities for future exploration. In the future, researchers can conduct studies on a larger scale by working with community-based organizations, non-profit organizations, and worship places to connect with BIP parents throughout the state. Strong relationships between parents and these organizations could encourage and ensure greater parental participation in research studies. Researchers can also include other family members such as grandparents, uncles, and aunts who may play a significant role in children's education and the influence of their roles in children's learning could also be investigated (Suizzo et al., 2014). Furthermore, on a professional level, the findings will provide educational stakeholders, social scientists and policy makers with an understanding that will enable them to respond effectively to the needs of diverse children. Therefore, due to the increase in immigrant minorities in U.S. schools, it is imperative to learn about various cultural backgrounds and, values and how they influence children's academic attainment. 


\section{Limitations}

All research studies have limitations (Bloomberg \& Volpe, 2012). One potential limitation is the sampling technique used for the study. The use of a purposive sampling technique to recruit a specific ethnic population, is a potential limitation. The focus of this study was to explore parents' experiences and perceptions of their behaviors related to their children's academic achievement. Although, the study findings were based on lengthy interviews, some parents' words may not have reflected their true views as they may have been influenced by social desirability. In addition, due to cultural and social barriers there were fewer female participants than male. Therefore, mother's experiences and perceptions of their involvement in their children's education were not fully represented due to the limited numbers of female participants in the study. Finally, despite the bracketing of prior experiences that is integral to a qualitative study, it is noteworthy to consider the role of researcher bias and the influence of the assumptions the researcher brings to the interpretation of the qualitative results (Creswell, 2013; Creswell \& Poth, 2018; LeaVasseur, 2003). The identification of one of the researchers as a Pakistani parent could be a limiting factor, as he was studying people from Pakistan and the study may have included his friends as participants.

\section{Funding Details}

The authors did not receive outside funding for this research project.

\section{Disclosure Statement}

The authors have no competing financial interests or personal relationships that have influenced the reported findings in this paper.

\section{References}

Ahmed, T. (2005). The Muslim marginal man. Policy, 21(1), 35-41.

Ajzen, I. (2002). Perceived behavioral control, self-efficacy, locus of control, and the theory of planned behavior. Journal of Applied Social Psychology, 32, 665-683. https://doiorg.ezproxy.fgcu.edu/10.1111/j.1559-1816.2002.tb00236.x

Ajzen, I. (2015). The theory of planned behaviour is alive and well, and not ready to retire: A commentary on Sniehotta, Presseau, and Araujo-Soares. Health Psychology Review, 9 (2), 131-137. https://doi.org/10.1080/17437199.2014.883474

Ajzen, I., \& Fishbein, M. (1972). Attitudes and normative beliefs as factors influencing behavioral intentions. Journal of Personality \& Social Psychology, 21(1), 1-9.

Alghazo,Y., \& Alghazo, R. (2015). The effect of parental involvement and socioeconomic status on elementary students' mathematics achievement. Journal of Social Sciences \& Humanities, 1(5), 521-527.

Ali, S. (2011). Perceived teacher and parental acceptance-rejection, and the academic achievement, adjustment, and behavior of children: Literature review. International Journal of Peace and Development Studies, 2(5), 138-147.

Arias, M. B., \& Morillo-Campbell, M. (2008). Promoting ELL parental involvement: Challenges in contested times [Policy brief]. Education Policy Research Unit, Arizona State University. 
Baker, C. E. \& Rimm-Kaufman, S. E. (2014). How homes influence schools: Early parenting predicts African American children's classroom social-emotional functioning. Psychology in the Schools, 51(7), 722-735. https://doi.org/10.1002/pits.21781

Baumrind, D. (1966). Effects of authoritative parental control on child behaviour. Child Development, 37(4), 887-907. https://doi.org/10.2307/1126611

Beauregard, F., Petrakos, H., \& Dupont, A. (2014). Family-school partnership: Practices of immigrant parents in Quebec, Canada. School Community Journal, 24(1), 177-210.

Benner, A., \& Yan, N. (2015). Classroom race/ethnic composition, family-school connections, and the transition to school. Applied Developmental Science, 10(3), 127-138. https://doi.org/10.1080/10888691.2014.983028

Berrington, A. (2018). Expectations for family transitions in young adulthood among the U.K. second generation. Journal of Ethnic and Migration Studies, 46(5), 913-935. https://doi.org/10.1080/1369183X.2018.1539276

Bhattacharya, G., \& Schoppelrey, S. L. (2004). Preimmigration beliefs of life success, postimmigration experience, and acculturative stress: South Asian immigrants in the United States. Journal of Immigrant Health, 6(2), 83-92. https://doi.org/10.1023/B:JOIH.0000019168.75062.36

Blair, S. L. (2014). Parental involvement and children's educational performance: A comparison of Filipino and U.S. Parents. Journal of Comparative Family Studies, 45(3), 351-366. http://www.jstor.org/stable/24339542

Bloomberg, L. D., \& Volpe, M. (2012). Completing your qualitative dissertation: A road map from beginning to end (2nd ed.). SAGE Publications.

Bogdan, R. C., \& Biklen, S. K. (2003). Qualitative research for education: An introduction to theories and methods (5th ed.). Pearson.

Bradley-Geist, J. C., \& Olson-Buchanan, J. B. (2014). Helicopter parents: An examination of the correlates of over-parenting of college students. Education and Training, 56(4), 314-328. https://doi.org/10.1108/ET-10-2012-0096.

Butler, J. L. (2016). Rediscovering Husserl: Perspectives on the epoche and the reductions. The Qualitative Report, 21(11), 2033-2043.

Cain, L. K., MacDonald, A. L. Coker, J. M., Velasco, J. C., \& West, G. D. (2019). Ethics and reflexivity in mixed methods research: An examination of current practices and a call for further discussion. International Journal of Multiple Research Approaches, 11(2), 144155. https://doi.org/10.29034/ijmra.v11n2a2

Chao, R. K. (2000). Cultural explanations for the role of parenting in the school success of Asian American children. In R. D. Taylor, \& M. C. Wang, (Eds.), Resilience across contexts: Family, work, culture, and community (pp. 333-363). Lawrence Erlbaum Associates.

Chao, R. K., \& Tseng, V. (2002). Parenting of Asians. In M. H. Bornstein (Ed.), Handbook of parenting: Vol. 4, Social conditions and applied parenting. Lawrence Erlbaum Associates.

Chao, R., Kanatsu, A., Stanoff, N., Padmawidjaja, I., \& Aque, C. (2009). Diversities in mean 7 ing and practices: The parental involvement of Asian immigrants. In N. E. Hill \& R. K. Chao (Eds.), Families, schools, and the adolescent: Connecting research, policy, and practice (pp. 110-125). Teachers College Press.

Child Trends (2015). Parental expectations for their children's academic attainment.

Clandinin, D. J., \& Connelly, F. M. (2000). Narrative inquiry: Experience and story in qualitative research (1st. ed.). Jossey-Bass. 
Coleman, B., \& McNeese, M. N. (2009). From home to school: The relationship among parental involvement, student motivation, and academic achievement. The International Journal of Learning, 16(7), 459-470.

Coleman, J. S., Campbell, E. Q., Hobson, C. J., McPartland, J., Mood, A. M., Weinfeld, F. D., \& York, R. L. (1966). Equality of educational opportunity. U.S. Government Printing Office.

Creswell, J. W. (2007). Educational research: Planning, conducting and evaluating quantitative and qualitative research (3rd ed.). Prentice Hall.

Creswell, J. W. (2012). Educational research: Planning, conducting and evaluating quantitative and qualitative research (4th ed.). Pearson.

Creswell, J. W. (2013). Steps in conducting a scholarly mixed methods study. DBER Speaker Series. $\quad \mathrm{http}: / /$ digitalcommons.unl.edu/cgi/viewcontent.cgi?article=1047\&context= berspeakers

Creswell, J. W. (2014). Research design: Quantitative, qualitative, and mixed methods approaches (4th ed.). SAGE Publications.

Creswell, J. W. (2015). Educational research: Planning, conducting, and evaluating quantitative and qualitative research (5th ed.). Pearson.

Creswell, J. W., \& Miller, D. L. (2000). Determining validity in qualitative inquiry. Theory Into Practice, 39(3), 124-130. https://doi.org/10.1207/s15430421tip39032

Creswell, J. W., \& Plano Clark, V. L. (2018). Designing and conducting mixed methods research (3rd ed.). SAGE Publications.

Creswell, J. W., \& Poth, C. N. (2018). Qualitative inquiry and research design: Choosing among five approaches (4th ed.). SAGE Publications.

Darder, A. (2016). Culture and power in the classroom: Educational foundations for the schooling of bicultural students. Routledge.

Dearing, E., McCartney, K., \& Taylor, B. A. (2006). Within-child associations between family income and externalizing and internalizing problems. Developmental Psychology, 42(2), 237-252. https://doi.org/10.1037/0012-1649.42.2.237

Denzin, N. K., \& Lincoln, Y. S. (Eds.). (2011). The SAGE handbook of qualitative research (5th. ed.). SAGE Publications.

Doepke, M., \& Zilibotti, F. (2017). Parenting with style: Altruism and paternalism in intergenerational preference transmission. Econometrica, 85(5), 1331-1371. https://doi.org/10.3982/ECTA14634

Doepke, M., \& Zilibotti, F. (2019). The economic roots of helicopter parenting. Phi Delta Kappan, 100(7), 22-27. https://doi.org/10.1177/0031721719841334

Dutt, K. (2009). The effect of family allocentrism and acculturation on the tendency to foreclose in second generation Indian college students (UMI 3354578) [Doctoral dissertation, The State University of New York at Albany]. Pro Quest Dissertations Publishing. https://search. proquest.com/openview/a8aa878b84da45d 88053a22b0ae3f534/1?pq-origsite= gscholar\&cbl $=18750 \&$ diss $=\mathrm{y}$

Eng, S., Szmodis, W., \& Mulsow, M. (2014). Cambodian parental involvement. The Elementary School Journal, 114(4), 573-594. https://doi.org/10.1086/675639

Enlund, E., Aunola, K., \& Nurmi, J. (2015). Stability in parents' causal attributions for their children's academic performance: A nine-year follow-up (EJ1079197). Journal of Developmental Psychology, 61(4), 509-536. ERIC. https://eric.ed.gov/?id=EJ1079197

Epstein, J. L. (2001). School, family, and community partnerships: Preparing educators and improving schools (1st ed.). Westview Press. 
Fan, X., \& Chen, M. (2001). Parental involvement and students' academic achievement: A metaanalysis. Educational Psychology Review, 13(1), 1-23. https://doi.org/10.1023/A:1009048817385

Fleming, J., \& Zegwaard, K. E. (2018). Methodologies, methods and ethical considerations for conducting research in work-integrated learning. International Journal of Work-Integrating Learning, 19(3), 205-213.

Fraenkel, J. R., Wallen, N. E., \& Hyun, H. H. (2015). How to design and evaluate research in education (9th ed.). McGraw-Hill Education.

Friend, M. (2018). Special education: Contemporary perspectives for school professionals. Pearson.

Giguere, B., Lalonde, R., \& Lou, E. (2010). Living at the crossroads of cultural worlds: The experience of normative conflicts by second generation immigrant youth. Social \& Personality Psychology Compass, 4(1), 14-29. https://doi.org/10.1111/j.17519004.2009.00228.x

Ginsburg, L., Rashid, H., \& English-Clarke, T. (2008). Parents learning mathematics: For their children, from their children, with their children. Adult Learning, 19(3/4), 21-26. https://doi.org/10.1177/104515950801900305

Gonida, E. N., \& Cortina, K. S. (2014). Parental involvement in homework: Relations with parent and student achievement-related motivational beliefs and achievement. British Journal of Educational Psychology, 84(3), 376-396. https://doi.org/10.1111/bjep.12039

Green, C. L., Walker, J. M. T., Hoover-Dempsey, K. V., \& Sandler, H. M. (2007). Parents' motivations for involvement in children's education: An empirical test of a theoretical model of parental involvement. Journal of Educational Psychology, 99(3), 532-544. https://doi.org/10.1037/0022-0663.99.3.532

Harris, A., Goodall, J. (2008). Do parents know they matter? Engaging all parents in learning. Educational Research, 50 (3). 277-289. https://doi.org/10.1080/00131880802309424

Hartas, D. (2015). Parenting for social mobility? Home learning, parental warmth, class and educational outcomes. Journal of Education, 31(1), 21-38. https://doi.org/10.1080/02680939

Henderson, A. T., \& Berla, N. (1994). A new generation of evidence: The family is critical to student achievement (ED375968). ERIC. https://files.eric.ed.gov/fulltext/ED375968.pdf

Henderson, A. T., \& Mapp, K. L. (2002). A new wave of evidence: The impact of school, family, and community connections on student achievement (ED474521). ERIC. https://eric.ed.gov/?id=ED474521

Hill, N. \& Chao, R. (Eds.). (2009). Families, schools and the adolescent: Connecting research, policy, and practice. Teachers College Press.

Hill, N. E., \& Tyson, D. F. (2009). Parental involvement in middle school: A meta-analytic assessment of the strategies that promote achievement. Developmental Psychology, 45(3), 740-763. https://doi.org/10.1037/a0015362

Hill, N. E., Witherspoon, D. P., \& Bartz, D. (2018). Parental involvement during middle school: Perspectives of ethnically diverse parents, teachers, and students. The Journal of Educational Research, 111(1), 12-27. https://doi.org/10.1080/00220671

Hoover-Dempsey, K. V., \& Sandler, H. (1995). Parental involvement in children's education: Why does it make a difference? Teachers College Record, 97(2), 310-331.

Hoover-Dempsey, K. V., \& Sandler, H. (1997). Why do parents become involved in their children's education? Review of Educational Research, 67(1), 3-42. https://doi.org/10.3102/00346543067001003 
Hoover-Dempsey, K. V., \& Sandler, H. (2005). The social context of parental involvement: A path to enhanced achievement. [Final performance report for OERI Grant \# R305T010673]. Institute of Educational Sciences, U.S. Department of Education. https://ir.vanderbilt.edu/bitstream/handle/1803/7595/OERIIESfinalreport032205.pdf?sequ ence $=1 \&$ is Allowed $=\mathrm{y}$

Hornby, G., \& Lafaele, R. (2011). Barriers to parental involvement in education: An explanatory model. Educational Review, 63(1), 37-52. https://doi.org/10.1080/00131911.2010.488049

https://www.childtrends.org/wp-content/uploads/2015/11/indicator_1448025709.541.pdf

Husserl, E. (1970). The crisis of European sciences and transcendental phenomenology: An introduction to phenomenological philosophy (1st ed.). Northwestern University Press.

Husserl, E. (2012). Ideas: General introduction to pure phenomenology. Routledge.

Ibrahim, F., Ohnishi, H., \& Sandhu, D. S. (1997). Asian American identity development: A culture specific model for South Asian Americans. Journal of Multicultural Counseling and Development, 25(1), 34-50. https://doi.org/10.1002/j.2161-1912.1997.tb00314.x

influence on science performance in the United States: The untold story. Education, 132(4), 725738.

Iqbal, H., \& Golombok, S. (2018). The generation game: Parenting and child outcomes in secondgeneration South Asian immigrant families in Britain. Journal of Cross-Cultural Psychology, 49(1), 25-43

Jeynes, W. H. (2011). Parental involvement and academic success. Routledge.

Jeynes, W. H. (2012). A meta-analysis of the efficacy of different types of parental involvement programs for urban education. Urban Education, 47(4), 706-742. https://doi.org/10.1177/0042085912445643

Jeynes, W. H. (2015). A meta-analysis: The relationship between father involvement and student academic achievement. Urban Education, 50(4), 387-423. http://dx.doi.org/10.1177/0042085914525789

Johnson, R. B., \& Christensen, L. (2020). Educational research: Quantitative, qualitative, and mixed approaches. SAGE Publications.

Kuru C. S., \& Taskin, P. (2016). Parent involvement in education in terms of their socio-economic status. Eurasian Journal of Educational Research, 66(1), 105-122. http://dx.doi.org/10.14689/ejer.2016.66.6

Kwon, K., Yoo, G., \& Bingham, G. E. (2016). Helicopter parenting in emerging adulthood: Support or barrier for Korean college students' psychological adjustment? Journal of Child \& Family Studies, 25(1), 136-145. https://doi.org/10.1007/s10826-015-0195-6.

Kwon, K., Yoo, G., \& De Gagne, J. C. (2017). Does culture matter? A qualitative inquiry of helicopter parenting in Korean American college students. Journal of Child \& Family Studies, 26(7), 1979-1990. https://doi.org/10.1007/s10826-017-0694-8

Lalonde, R.N., Hynie, M., Pannu, M., \& Tatla, S. (2004). The role of culture in interpersonal relationships: Do second-generation South Asian Canadians want a traditional partner? Journal of Cross-Cultural Psychology, 35(5), 503-524. http://dx.doi.org/10.1177/0022022104268386

Lau, W. K. (2013). Examining a brief measure of parent involvement in children's education. Contemporary School Psychology, 17(1), 11-21. https://doi.org/10.1007/BF03340985

Lechuga-Pena, S., \& Brisson, D. (2018). Barriers to school-based parent involvement while living in public housing: A mother's perspective. The Qualitative Report, 23(5), 1176-1187. 
Lee, J.-S., \& Bowen, N. K. (2006). Parent involvement, cultural capital, and the achievement gap among elementary school children. American Educational Research Journal, 43(2), 193218. https://www-jstor-org.ezproxy.fgcu.edu/stable/3699418

LeMoyne, T., \& Buchanan, T. (2011). Does "hovering" matter? Helicopter parenting and its effect on well-being. Sociological Spectrum, 31(4), 399-418. https://doi.org/10.1080/02732173.2011.574038

Leonard, K. I. (1997). The South Asian Americans. Greenwood Press.

LeVasseur, J. J. (2003). The problem of bracketing in phenomenology. Qualitative Health Research, 13(3), 408-420. https://doi.org/10.1177/1049732302250337

Levin, I., \& Aram, D. (2012). Mother-child joint writing and storybook reading and their effects on kindergartners' literacy: An intervention study. Reading and Writing, 25(1), 217-249. https://doi.org/10.1007/s11145-010-9254-y

Li, H., Martin, A. J., \& Yeung, W.-J. J. (2017). Academic risk and resilience for children and young people in Asia. Educational Psychology, 37(8), 921-929. https://doi.org/10.1080/01443410.2017.13319 73.

Lincoln, Y. S., \& Guba, E. G. (1985). Naturalistic inquiry. SAGE Publications.

Lindberg, E. N., \& Demircan, A. N. (2013). Parental participation at high school: Adaptation of teachers' and parents' scales of parental participation. Cumhuriyet International Journal of Education, 2(3), 64-78

Martinez, M. E. (2010). Learning and cognition: The design of the mind. Pearson.

McGregor, S. A., \& Knoll, M. A. (2015). The theory of planned behavior as a framework for understanding parental experiences with homework. Educational Psychology in Practice, 31(4), 335-353. http://dx.doi.org/10.1080/02667363.2015.1065472

Merriam, S. B. (2009). Qualitative research: A guide to design and implementation. John Wiley \& Sons.

Miles, M. B., \& Huberman, A. M. (1994). Qualitative data analysis: An expanded source book. SAGE Publications.

Mostafa, T., Gambaro, L., \& Joshi, H. (2018). The impact of complex family structure on child well-being: Evidence from siblings. Journal of Marriage and Family, 80(8), 902-918. https://doi.org/10.1111/jomf.12456

Moustakas, C. (1994). Phenomenological research methods. SAGE Publications.

National Center for Education Statistics. (2020). Racial/ethnic enrollment in public schools. https://nces.ed.gov/programs/coe/indicator_cge.asp.

Ngo, B. (2006). Learning from the margins: The education of Southeast and South Asian Americans in context. Race, Ethnicity and Education, 9(1), 51-65. https://doi.org/10.1080/13613320500490721

Ogbu, J. U. (1992). Adaptation to minority status and impact on school success. Theory into Practice. 31(4), 287-295. https://doi.org/10.1080/00405849209543555

Otto, W. J. (2016). What teachers should know about why these students perform so well: An examination of Korean American achievement through student perspectives of East Asia parenting beliefs, styles and practices (EJ1126677). International Electronic Journal of Elementary Education, 8(4), 167-181. ERIC. https://eric.ed.gov/?id=EJ1126677.

Padilla-Diaz, M. (2015). Phenomenology in educational qualitative research: Philosophy as science or philosophical science. International Journal of Educational Excellence, 1(2). 101-110. https://doi.org/10.18562/IJEE.2015.0009

Padilla-Walker, L. M., \& Nelson, L. J. (2012). Black hawk down?: Establishing helicopter parenting as a distinct construct from other forms of parental control during emerging 
adulthood. Journal of Adolescence, 35(5), 1177-1190. https://doi.org/10.1016/j.adolescence.2012.03.007

Paik, S. J., Rahman, Z., Kula, S. M., Saito, L. E., \& Witenstein, M. A. (2017). Diverse Asian American families and communities: Culture, structure, and education (Part 1: Why they differ). School Community Journal, 27(2), 35-66.

Park, S., \& Holloway, S. (2018). Parental involvement in adolescents' education: An examination of the interplay among school factors, parental role, construction, and family income (EJ1184925). School Community Journal, 28(1). 9-36. $\quad$ ERIC. https://files.eric.ed.gov/fulltext/EJ1184925.pdf.

Patel, N., \& Stevens, S. (2010). Parent-teacher-student discrepancies in academic ability beliefs: Influences on parent involvement. School Community Journal, 20(2), 115-136

Patrikakou, E. N., Weissberg, R. P., Redding, S., \& Walberg, H. J. (2005). School-family partnerships for children's success. Teachers College Press.

Patton, M. Q. (2002). Qualitative research and evaluation methods. SAGE Publications.

Pew Research Center. (2012). The rise of Asian Americans. Pew Social \& Demographics Trends. https://www.immigrationresearch.org/system/files/PewResearch---Rise-of-AsianAmericans.pdf

Pew Research Center. (2015). How U.S. immigration laws and rules have changed through history. News in the Numbers. https://www.pewresearch.org/fact-tank/2015/09/30/how-u-simmigration-laws-and-rules-have-changed-through-history/

Pew Research Center. (2017). Key facts about Asian Americans, a diverse and growing population. Pew Social \& Demographics Trends. https://www.pewresearch.org/facttank/2017/09/08/key-facts-about-asian-americans

Pinder, P. J. (2012). Afro-Caribbean and African American students, family factors, and the

Pomerantz, E. M., Moorman, E. A., \& Litwack, S. D. (2007). The how, whom, and why of parents' involvement in children's academic lives: More is not always better. Review of Educational Research, 77(3), 373-410. https://doi.org/10.3102/003465430305567

Purkayastha, B. (2005). Negotiating ethnicity: Second-generation South Asian Americans traverse a transnational world. Library of Congress.

Rahman, Z., \& Witenstein, M. A. (2014). A quantitative study of cultural conflict and gender differences in South Asian American college students. Ethnic and Racial Studies, 37(6), 1121-1137. https://doi.org/10.1080/01419870.2012.753152

Rasool, S., Zhang, J., Halpern, C., Paz, S., Aydin, H. \& Wang, X. (2020). Developing an instrument to measure impacts of south Asian parental behavior on children's academic achievement in USA. In Huang, L., Zheng, N., Lin, Q., Huang, R., Guo, S., \& Guo, J. (Eds). (2020). Proceedings of the 24th Global Chinese Conference on Computers in Education (GCCCE2019). Taibei: Global Chinese Society for Computers in Education, ISBN 9789869839921, pp.741-744.

Raty, H., \& Kasanen, K. (2010). A seven-year follow-up study on parents' expectations of their children's future education. Journal of Applied Social Psychology, 40(11), 2711-2735.

Roy, M., \& Giraldo-Garcia, R. (2018). The role of parental involvement and social/emotional skills in academic achievement: Global perspectives (EJ1201955). School Community Journal, 28(2), 29-46. ERIC. https://eric.ed.gov/?id=EJ1201955

Sandhu, D. S., \& Madathil, J. (2008). South Asian Americans. In G. McAuliffe, \& Associates (Eds.), Culturally alert counseling: A comprehensive introduction (Vol. 1, pp. 353-388). Sage Publications, Inc. 
Saran, R. (2007). Model minority imaging in New York: The situation with second generation Asian Indian learners in middle and secondary schools. Anthropologist Special Issue, 2, 67-79.

Schiffrin, H. H., Liss, M., Miles-McLean, H., Geary, K. A., Erchull, M. J., \& Tashner, T. (2014). Helping or hovering? The effects of helicopter parenting on college students' well-being. Journal of Child and Family Studies, 23, 548-557. https://doi.org/10.1007/s10826-0139716-3

Seginer, R. (2006). Parents' educational involvement: A developmental ecology perspective. Parenting: Science and Practice, 6(1), 1-48. https://doi.org/10.1207/s15327922par0601_1

Segrin, C., Givertz, M., Swaitkowski, P., \& Montgomery, N. (2015). Overparenting is associated with child problems and a critical family environment. Journal of Child \& Family Studies, 24(1), 470-479. https://doi.org/10.1007/s10826-013-9858-3.

Segrin, C., Woszidlo, A., Givertz, M., Bauer, A., \& Murphy, M. T. (2012). The association between overparenting, parent-child communication, and entitlement and adaptive traits in adult children. Family Relations, 61(2), 237-252. https://doi.org/10.1111/j.17413729.2011.00689.x.

Shariff, A., (2009). Ethnic identity and parenting stress in South Asian families: Implications for culturally sensitive counselling. Canadian Journal of Counselling, 43(1), 35-56.

Skinner, B. F. (1989). Recent issues in the analysis of behavior. Merrill.

Spera, C. (2005). A review of the relationship among parenting practices, parenting styles, and adolescent school achievement. Educational Psychology Review, 17(2), 125https://doi.org/146. 10.1007/s10648-005-3950-1

Suizzo, M., Pahlke, E., Yarnell, L., Chen, K., \& Romero, S. (2014). Home-based parental involvement in young children's learning across U.S. ethnic groups: Cultural models of academic socialization. Journal of Family Issues, 35(2), 254-287. https://doi.org/10.1177/0192513X12465730

Sy, S. R., \& Schulenberg, J. E. (2005). Parent beliefs and children's achievement trajectories during the transition to school in Asian American and European American families. International Journal of Behavioral Development, 29(6), 505-515. https://doi.org/10.1080/01650250500147329

Taylor, A., Krahn, H. (2013). Living through our children: Exploring the education and career choices of racialized immigrant youth in Canada. Journal of Youth Studies, 68(1), 10001021. https://doi.org/10.1080/13676261.2013.772575

Tran, K., Kaddatz, J., \& Allard, P. (2005). South Asians in Canada: Unity through diversity. Canadian Social Trends, 78(1), 20-25.

U.S. Census Bureau. (2010). Population and housing unit counts:2010. https://www.census.gov/prod/cen2010/cph-2-1.pdf

Uddin, M. K. (2011). Parental warmth and academic achievement of adolescent children. Journal of Behavioral Sciences, 21(1), 1-12.

Vera, E. M., Israel, M. S., Coyle, L., Cross, J., Lynn, L., Moallem, I., Bartucci, G., \& Goldberger, N. (2012). Exploring the educational involvement of parents of English learners (EJ1001618.) School Community Journal, 22(2), 183-202. ERIC. https://eric.ed.gov/?id=EJ1001618

Verma, R. (2008). Backlash: South Asian immigrant voices on the margins. Sense Publishers.

Walker, J. M. T., Shenker, S. S., \& Hoover-Dempsey, K. (2010). Why do parents become involved in their children's education? Implications for school counselors. Professional School Counseling, 14(1), 27-41. 
Wang, Q., Pomerantz, E. M., \& Chen, H. (2007). The role of parents' control in early adolescents' psychological functioning: A longitudinal investigation in the United States and China. Child Development, 78(5), 1592-1610. https://doi.org/10.1111/j.1467-8624.2007.01085.x.

Wang, Y., Deng, C., \& Yang, X. (2016). Family economic status and parental involvement: Influences of parental expectation and perceived barriers. School Psychology International, 37(5), 536-553. https://doi.org/10.1177/0143034316667646

Wilder, S. (2014). Effects of parental involvement on academic achievement: A meta-synthesis. Educational Review, 66(3), 377-397. https://doi.org/10.1080/00131911.2013.780009

World O Meters (2020). Southern Asia population. https://www.worldometers.info/worldpopulation/southern-asia-population/

Yamamoto, Y., \& Holloway, S. D. (2010). Parental expectations and children's academic performance in sociocultural context. Educational Psychology Review, 22(3), 189-214. https://doi.org/10.1007/s10648-010-9121-z

Yanghee, A. K., Sohyun, A., Hyun, C. L. K., \& Jihye, K. (2018). Meaning of parental involvement among Korean immigrant parents: A mixed methods approach. The Journal of Education Research, 111(2), 127-138. https://doi.org/10.1080/00220671.2016.1220355.

Yildirim, S. (2019). Predicting mathematics achievement: The role of socioeconomic status, parental involvement, and self-confidence. Education and Science, 44(198), 99-113. https://doi.org/10.15390/EB.2019.7868

Yin, R. K. (2005). Case study research: Design and methods. SAGE Publishing.

Yin, R.K. (2016). Qualitative research from start to finish (2nd ed.). The Guilford Press.

Yuen, L. H. (2011). Enhancing home-school collaboration through children's expression. European Early Childhood Education Research Journal, 19(1), 147-158. https://doi.org/10.1080/1350293X.2011.548963

\section{Notes on Contributor}

The first author is a research assistant, a doctoral candidate, and a South Asian parent. The second author is an associate professor, and a parent from Asia. The researchers have a keen interest in this project because of their expertise and research interests in regional studies, multicultural education, and parental involvement activities at home and at school that enhance children's academic achievement.

Manuscript received November 1, 2020 Final revision received December 14, 2020

Accepted December 14, 2020 